\title{
Produtividade de genótipos de batata inglesa tolerantes ao calor em duas épocas de plantio, no vale do São Francisco.
}

\author{
José Egídio Flori; Geraldo Milanez de Resende \\ Embrapa Semi-Àrido, C. Postal 23, 56.300-000 Petrolina-PE. e-mail: gmilanez@ufla.br
}

\begin{abstract}
RESUMO
Com o objetivo de avaliar diferentes genótipos de batata tolerantes ao calor em duas épocas de plantio (inverno e primavera), instalaram-se dois experimentos no Campo Experimental de Bebedouro da Embrapa Semi-Árido, Petrolina (PE). O delineamento experimental foi blocos ao acaso com quatro repetições, utilizando-se os genótipos LT-9, 301251-1, 311320-1, 301217-1, 301159-1, Serrana x DTO-33 e a variedade comercial Baraka como testemunha. $\mathrm{Na}$ condição de clima quente (média de $25,8^{\circ} \mathrm{C}$ ), o genótipo LT-9 apresentou a maior produtividade comercial $(10,3 \mathrm{t} / \mathrm{ha})$, seguido pelos demais tratamentos que não mostraram diferenças estatísticas entre si, à exceção de Serrana x DTO-33 que apresentou a menor produtividade $(2,7 \mathrm{t} / \mathrm{ha})$. $\mathrm{O}$ cultivo na condição de clima mais frio (média de $24,7^{\circ} \mathrm{C}$ ), a produtividade total variou de $17,5 \mathrm{t} / \mathrm{ha}$ a $23,3 \mathrm{t} / \mathrm{ha}$, sendo que o genótipo 301251-1 alcançou a maior produtividade (23,3 t/ha), não se verificando diferença estatística entre os tratamentos. Pelos resultados preliminares obtidos há indicação que os genótipos 301251-1, 311320-1; 301217-1 e 301159-1 podem ser plantados de abril a agosto como alternativas de cultivo à cultivar Baraka, necessitando, porém, de maiores investigações.
\end{abstract}

Palavras-chave: Solanum tuberosum, genótipos, adaptação.

\begin{abstract}
Productivity of heat tolerant potato genotypes in two planting times in São Francisco Valley, Northeast of Brazil.

The experiments were carried out at the Bebedouro Experimental Field of Embrapa Semi-Àrid Research Center in Petrolina, Brazil, to evaluate different heat tolerant potato genotypes under two climatic conditions. The experimental design was of randomized complete blocks with seven genotypes (LT-9, 301251-1, 311320-1, 3012171, 301159-1, Serrana x DTO-33 and cv. Baraka) and four replications. Under hot climatic condition $\left(28^{\circ} \mathrm{C}\right)$ the genotype LT-9 showed the highest commercial yield (10.3 $\mathrm{t} / \mathrm{ha}$ ), followed by the other treatments that didn't show statistical differences in relation to each other, except the genotype Serrana x DTO-33 which showed the lowest commercial yield $(2.7 \mathrm{t} / \mathrm{ha})$. Under favorable condition $\left(23^{\circ} \mathrm{C}\right)$, the commercial yield varied from 17.5 to $23.3 \mathrm{t} / \mathrm{ha}$, whereas the genotype 301251-1 showed the highest yield $(23.3 \mathrm{t} / \mathrm{ha})$ but there were no statistical differences between the different treatments. The results indicated that the genotypes LT-9, 301251-1, 311320-1 and 301217-1 could be cultivated during the hot season and the genotypes 311251-1, 301217-1 and 311320-1 could be cultivated under favorable conditions as an alternative to the Baraka variety. However more investigation is needed.
\end{abstract}

Keywords: Solanum tuberosum, yield, adaptation.

(Aceito para publicação em 17 de maio de 2.000)

\begin{abstract}
$\mathrm{A}^{\mathrm{b}}$ batata (Solanum tuberosum L.), em termos mundiais, é considerada a terceira fonte alimentar da humanidade sendo suplantada apenas pelo arroz e trigo. No Brasil, ocupa o primeiro lugar entre as olerícolas em área cultivada em termos de produção e valor econômico
\end{abstract}

(Filgueira, 1995). O rendimento médio nacional é de 14,48 t/ha, sendo que o Estado de Pernambuco apresenta um produtividade média de 9,25 t/ha, para uma área cultivada de 4.830 hectares. No Nordeste e no Norte do Brasil o consumo por habitante/ano é ainda muito baixo, em torno de $2,4 \mathrm{~kg}$, sendo que na região Sul e Sudeste é de aproximadamente de $15 \mathrm{~kg}$ (ANUÁRIO ESTATÍSTICO DO BRASIL, 1996).

A batata é originária da região Andina e foi melhorada, geneticamente, nos países de clima temperado em 
Produtividade de genótipos de batata inglesa tolerantes ao calor em duas épocas de plantio, no vale do São Francisco.

Tabela 1. Dados climáticos no período de cultivo da cultura da batata inglesa na Estação Experimental de Bebedouro. Petrolina, Embrapa Semi-Árido,1996.

\begin{tabular}{lcccccccc}
\hline \multirow{2}{*}{ Variável climática } & \multicolumn{4}{c}{$\mathbf{1 9 9 5}$} & & \multicolumn{3}{c}{$\mathbf{1 9 9 6}$} \\
\cline { 2 - 3 } \cline { 7 - 8 } & Agosto & Setembro & Outubro & & abril & & Maio & junho \\
\hline Temp. média mensal $\left({ }^{\circ} \mathrm{C}\right)$ & 24,4 & 25,7 & 27,3 & & 25,6 & & 25,0 & 23,5 \\
Temp. mínima mensal $\left({ }^{\circ} \mathrm{C}\right)$ & 18,6 & 19,9 & 21,8 & & 19,9 & 18,5 & 17,8 \\
Temp. máxima mensal $\left({ }^{\circ} \mathrm{C}\right)$ & 31,4 & 32,9 & 35,2 & & 31,0 & 30,9 & 29,7 \\
Precipitação $(\mathrm{mm})$ & 1,20 & 0,00 & 0,00 & & 87,7 & 25,5 & 17,1 \\
Umidade relativa (\%) & 57 & 56 & 51 & & 83 & 85 & 74 \\
Evaporação diária $(\mathrm{mm})$ & 7,2 & 8,8 & 9,2 & & 5,0 & 5,5 & 5,3 \\
Insolação média diária $(\mathrm{h})$ & 7,2 & 9,0 & 9,1 & & 6,0 & & 4,4 & 7,4 \\
\hline
\end{tabular}

condições de dias longos, sendo, portanto, as variedades cultivadas atualmente intensamente influenciadas pelo clima. No Brasil como não há grandes variações no comprimento do dia, exceto na região sul, as maiores produtividades são obtidas sob condição de dias frios (Antunes \& Fortes, 1981). Trabalho realizado por Wolf et al. (1991) identificaram a influência negativa da alta temperatura na produtividade da cultura da batata, manifestada pelo aumento do metabolismo da planta e, consequentemente, pela perda da eficiência fotossintética. Sabe-se que a temperatura tem influência direta na tuberização. A temperatura variando de 14 a $18^{\circ} \mathrm{C}$, é indispensável para uma completa e perfeita tuberização, ao contrário das temperaturas acima de $30^{\circ} \mathrm{C}$ que inibem e, até mesmo, impedem que a mesma aconteça (Bittencourt et al., 1985; Lopes et al., 1996).

Trabalhos que visam a adaptação de cultivares às condições de altas temperaturas têm sido relatados por diferentes autores (Levy, 1986; Manrique \& Bartholomew, 1991; Midmore \& Roca, 1992). Apesar de se produzir melhor em clima frio, com temperatura média inferior a $23^{\circ} \mathrm{C}$, é possível cultivar a batata em regiões de temperaturas mais elevadas no Nordeste brasileiro; entretanto, é esperado um rendimento menor da cultura. Em condições experimentais tem-se conseguido até $30 \mathrm{t} / \mathrm{ha}$ (Silva et al., 1993); sendo que em relação aos produtores têm-se verificado produções de 15 a 20 t/ha (Silva et al., 1993; Pereira et al., 1993). Rendimentos de 17,8 $\mathrm{t} /$ ha foram obtidos por Flori (1995) com a cultivar Baraka, com plantio no mês de maio. Salientando-se que todos estes trabalhos foram conduzidos em épocas mais frias destas regiões.

Avaliando-se cultivares de batata no Estado da Paraíba, Silva (1987) obteve produtividades variando de 4,0 a 14,5 t/ ha, destacando-se a cultivar Baraka como a mais produtiva. Esta cultivar também foi recomendada por Filgueira (1984) para condições de temperaturas mais elevadas. Vale ressaltar que a produtividade média estadual de 9,25 t/ha é muito baixa (ANUÁRIO ESTATÍSTICO DO BRASIL, 1996). Embora o nível tecnológico da maioria dos produtores pernambucanos seja o principal fator responsável pela baixa produtividade do Estado, as altas temperaturas também contribuem para a redução da produção.

Este trabalho teve o objetivo de avaliar a produção de seis clones de batata inglesa tolerantes ao calor, em duas épocas do ano, visando uma maior produtividade no Vale do São Francisco.

\section{MATERIAL E MÉTODOS}

Foram conduzidos dois experimentos na Estação Experimental de Bebedouro do Centro de Pesquisa Agropecuária do Trópico Semi-Árido Embrapa Semi-Árido, Petrolina - PE. A análise química prévia do solo da área experimental apresentou as seguintes concentrações na camada de 0-20 cm: $\mathrm{K}=0,12, \mathrm{Ca}=1,4 ; \mathrm{Mg}=0,4 ; \mathrm{Na}=0,17$, $\mathrm{H}+\mathrm{Al}=0,05$ em cmolc $/ \mathrm{dm}^{3}$ de solo; $\mathrm{P}$ $=55,80 \mathrm{mg} / \mathrm{kg}$; matéria orgânica $=0,44$ $\%$ e $\mathrm{pH}=6,5$ em $\mathrm{H}_{2} 0$, utilizando-se a metodologia descrita pela EMBRAPA (1979). Os dados climáticos registrados no período de execução dos experimentos são apresentados na Tabela 1.
Utilizou-se o delineamento em blocos ao acaso com sete tratamentos e quatro repetições. Os genótipos avaliados foram selecionados para tolerância ao calor pela Embrapa Hortaliças, sendo os seguintes: LT-9, 301251-1, 311320-1, 301217-1, 5301159-1, Serrana x DTO33 e a cultivar Baraka que foi empregada como testemunha. $\mathrm{O}$ espaçamento empregado foi de $80 \mathrm{~cm}$ entre linha e 20 $\mathrm{cm}$ entre plantas, sendo que a área útil das parcelas de $9,6 \mathrm{~m}^{2}$ e $4,8 \mathrm{~m}^{2}$, respectivamente para o plantio nas épocas outono/inverno e inverno/primavera.

O plantio da batata na época mais quente, safra inverno/primavera, foi realizado em 22/08/95. Neste experimento foram utilizados todos os genótipos descritos anteriormente. O plantio da batata na época mais fria, safra outono/inverno, foi realizado em 22/04/96, sendo empregados os mesmos genótipos do plantio anterior com exceção do genótipo Serrana x DTO-33.

As batatas-semente empregadas no experimento instalado em 1995, safra inverno/primavera, foram oriundas de cultura de tecidos, as quais após o primeiro cultivo foram colhidas e armazenadas em câmara frigorífica e posteriormente utilizadas no plantio do experimento instalado em 1996, safra outono/inverno. A adubação de plantio foi equivalente a $1.000 \mathrm{~kg} / \mathrm{ha}$ do adubo formulado 6-24-12, sendo realizada uma de cobertura equivalente a $100 \mathrm{~kg} / \mathrm{ha}$ de $\mathrm{Ne} 150 \mathrm{~kg} /$ ha de $\mathrm{K}_{2} \mathrm{O}$ aos 20 dias do plantio. Aplicou-se $2 \mathrm{~kg} / \mathrm{ha}$ do princípio ativo Phorate a $5 \%$ no sulco de plantio.

As irrigações foram realizadas através de aspersão convencional, duas vezes por semana, com lâmina de água 
Tabela 2. Produção total e comercial, cor e aspecto da película e formato de seis genótipos de batata tolerantes ao calor, cultivados na época mais quente, no vale do São Francisco. Petrolina, Embrapa Semi-Árido, 1995.

\begin{tabular}{lcccc}
\hline Genótipos & $\begin{array}{c}\text { Produtividade Total } \\
(\mathbf{~ k g} / \mathbf{h a})\end{array}$ & $\begin{array}{c}\text { Produtividade } \\
\text { Comercial (kg/ha) }\end{array}$ & $\begin{array}{c}\text { Cor e aspecto da } \\
\text { Película }\end{array}$ & Formato \\
\hline LT-9 & $12,3 \mathrm{a}$ & $10,3 \mathrm{a}$ & Amarela-aspera & Arredondado \\
$301251-1$ & $12,2 \mathrm{a}$ & $9,7 \mathrm{a}$ & Amarela-lisa & Arredondado \\
$311320-1$ & $10,0 \mathrm{a}$ & $8,6 \mathrm{a}$ & Amarela-lisa & Arredondado \\
$301217-1$ & $11,2 \mathrm{a}$ & $8,0 \mathrm{a}$ & Amarela-lisa & Arredondado \\
$301159-1$ & $9,0 \mathrm{a}$ & $7,4 \mathrm{a}$ & Amarela-lisa & Arredondado \\
Baraka & $12,3 \mathrm{a}$ & $7,1 \mathrm{a}$ & Amarela-lisa & Arredondado \\
Ser.x DTO-33 & $6,3 \mathrm{~b}$ & $2,7 \mathrm{~b}$ & Amarela-lisa & Arredondado \\
\hline Média & 10,5 & 7,7 & &
\end{tabular}

*Médias seguida da mesma letra na coluna, não diferem entre si pelo teste de Tukey a $(p=0,05)$

${ }^{1}$ Tubérculos com diâmetro acima de $28 \mathrm{~mm}$.

Tabela 3. Produtividade total e comercial de seis genótipos de batata, tolerantes ao calor, cultivados na época mais fria, no vale do São Francisco. Petrolina, Embrapa Semi-Árido, 1996.

\begin{tabular}{lcc}
\hline \multirow{2}{*}{ Genótipos } & \multicolumn{2}{c}{ Produtividade $(\mathbf{K g} / \mathbf{h a})$} \\
\cline { 2 - 3 } & Total & comercial $^{2}$ \\
\hline LT-9 & $17,5 \mathrm{a}$ & $14,5^{*} \mathrm{a}$ \\
$311320-1$ & $20,8 \mathrm{a}$ & $17,3 \mathrm{a}$ \\
$301217-1$ & $21,9 \mathrm{a}$ & $18,4 \mathrm{a}$ \\
$301251-1$ & $23,3 \mathrm{a}$ & $18,9 \mathrm{a}$ \\
$301159-1$ & $18,2 \mathrm{a}$ & $14,8 \mathrm{a}$ \\
Baraka & $20,0 \mathrm{a}$ & $17,2 \mathrm{a}$ \\
\hline Média & 16,8 & 20,3
\end{tabular}

* Médias seguida da mesma letra na coluna, não diferem entre si pelo teste de Tukey $(\mathrm{p}=0,05)$

2 tubérculos acima de $28 \mathrm{~mm}$ de diâmetro

calculada com base na evaporação do tanque classe "A" e o coeficiente da cultura correspondente ao estádio fenológico da cultura, conforme Doorembos \& Kassam (1994). Os tratos fitossanitários foram realizados com intervalos de quinze dias sempre alternando-se os princípios ativos dos produtos para controle de pragas e doenças na a cultura.

$\mathrm{Na}$ colheita as seguintes características foram avaliadas: produtividade total e comercial (tubérculos maiores que $28 \mathrm{~mm}$ de diâmetro), formato, cor e aspecto da película dos tubérculos e ciclo da cultura. Posteriormente, foi feita a análise de variância, aplicando-se o teste Tukey no nível de $5 \%$ de probabilidade para comparação das médias.

\section{RESULTADOS E DISCUSSÃO}

Verificou-se que a produtividade dos genótipos, no período mais quente da região que começa a partir de agosto, variou de $6,3 \mathrm{t} /$ ha a $12,3 \mathrm{t} /$ ha e $2,7 \mathrm{t} /$ ha a $10,3 \mathrm{t} / \mathrm{ha}$, respectivamente, para produtividade total e comercial (Tabela 2). Neste cultivo destacou-se o genótipo LT-9 como a maior produtividade comercial (10,3 t/ha), não havendo diferenças estatísticas em relação aos demais, à exceção de Serrana x DTO-33, que apresentou a menor produtividade (2,7 t/ha), mostrando-se totalmente inadaptado às condições locais de cultivo. Apesar de não se observar diferenças estatísticas entre os genótipos mais produtivos, salienta-se que os genótipos LT-9, 301251-1 e 311320-1 foram 45\%, $36 \%$ e $21 \%$, respectivamente, mais produtivos que a cultivar Baraka, que é a variedade mais recomendada para regiões com temperaturas altas, segundo Filgueira (1984). Estes resultados indicam a possibilidade de ganhos por seleção, demonstrando que um correto direcionamento na estratégia de melhoramento poderá resultar na obtenção de genótipos mais tolerantes ao calor.

Com relação à cor e ao aspecto da película, bem como ao formato do tubérculo, verificou-se uma similaridade de comportamento dos genótipos em relação à cultivar Baraka, excetuandose LT-9, que mostrou a película mais áspera (Tabela 2).

A produtividade no experimento, cultivado sob condições de clima mais frio, variou de $17,5 \mathrm{t} / \mathrm{ha}$ a $23,3 \mathrm{t} / \mathrm{ha}$ e de $14,5 \mathrm{t} /$ ha a $17,2 \mathrm{t} / \mathrm{ha}$, respectivamente, para produtividade total e comercial, não mostrando diferenças estatísticas entre os tratamentos. Contudo, para os genótipos 301251-1 e 301217-1, verificaram-se níveis de produtividade superiores à cultivar Baraka, de 16,5 e 9,5\%, respectivamente. Estes resultados são superiores aos encontrados por Silva (1987) e Flori (1995), assim como a média nacional, que é de 14,48 t/ha, suplantando ainda a produtividade média estadual em $100 \%$, no caso do genótipo mais produtivo (301251-1 com 18,9 t/ha).

Com relação ao ciclo da cultura, verificou-se para o experimento em condições de clima mais quente um ciclo de 75 dias, enquanto para cultivo realizado na época mais fria o ciclo médio foi de 80 dias. A pequena diferença observada entre os ciclos foi influenciada pelo estado físiológico das batatas-semente no momento do plantio. Enquanto as batatas-semente do plantio realizado na época mais quente estavam jovens fisiológicamente, as batatas-semente cultivadas na época mais fria 
encontram-se fisiológicamente mais velhas. É sabido que a idade fisiológica afeta o ciclo da cultura da batata, de forma que quanto mais velha, mais curto será o ciclo da cultura. Dessa forma que a idade fisiológica mais avançada no experimento plantado no época mais amena contrapôs a temperatura mais amena diminuindo o ciclo da cultura. Por outro lado as batatas-semente cultivadas no período mais quente por serem mais jovens fisiológicamente propiciaram um ciclo cultural mais longo.

Comparando-se a produtividade média nas duas épocas de plantio, verificou-se que o cultivo no período mais frio suplantou em $118 \%$ a produtividade obtida no cultivo sob condições de clima mais quente. Este diferencial de produtividade respalda o efeito depreciativo da alta temperatura na produtividade da cultura nas condições do Vale do São Francisco. A diminuição da produtividade observada neste trabalho corrobora com os autores Antunes \& Fortes (1981), Bittencurt et al. (1995) e Lopes (1996), que correlacionam a diminuição da produção com aumento da temperatura.

Pelos resultados preliminares obtidos, nas duas épocas de cultivo avaliados, os genótipos 301251-1, 311320-1, 301217-1 e 301159-1 poderão ser usados como alternativa de plantio à cultivar Baraka, necessitando, porém, de mais avaliações em cultivos demonstrativos ou mesmo em escala comercial.

\section{LITERATURA CITADA}

ANTUNES, F.L.; FORTES, M. Exigências climáticas da cultura da batata. Informe Agropecuário, Belo Horizonte, v. 7, n. 76, p. 19-23, 1981.

ANUÁRIO ESTATÍSTICO DO BRASIL. Rio de Janeiro, IBGE. v. 56, 1996.

ARAÚJO, J.P. DE; DÓLIVEIRA, L.O.B. Ensaio de competição de cultivares de batata (Solanum tuberosum, L.) sob irrigação. Petrolina - PE: SUVALE, Estação Experimental de Bebedouro, [s. d]. 3 p.

BITTENCOURT, C.; REISFSCHNEIDER, F.J.B.; MAGALHÃES, J.R. de; FURUMOTO, O.; FEDALTO, A.A.; MAROUELLI, W.A.; SILVA. H.R. da; FRANÇA, F.H.; D' AVILA, A.C.; GIORDANO, L.B. Cultura de batata (Solanum tuberosum L.). Brasília: EMBRAPA-CNPH, 1985. 19 p. (EMBRAPACNPH. Instruções técnicas).

DOORENBOS, J.; KASSAM, A.M. Efeito da água no rendimento das culturas. Campina Grande: RFPB, 1994. p. 40. (FAO. Estudos Irrigação e Drenagem, 33).

EMBRAPA. Serviço Nacional de Levantamento e conservação de Solos. Manual de métodos de análises de solo. Rio de Janeiro: 1979. $1 \mathrm{v}$.

FILGUEIRA, F.A.R. Bataticultura - uma boa opção para o sul de Goiás. Goiânia: EMGOPA, 1984. 18 p. (EMGOPA. Circular Técnica, 6).

FILGUEIRA, F.A.R. Melhoramento genético de batata para regiões de cerrado - um depoimento pessoal. Horticultura Brasileira, Brasília, v. 13, n. 2, p. 129-132, 1995.

FLORI, J.E. Avaliação da produção de batatinha, cv. Baraka, cultivada sob irrigação na safra de inverno em Petrolina. Petrolina, PE, 1995. Trabalho apresentado no I Encontro Técnico de Bataticultura do Nordeste, Petrolina, PE, 1995. (não publicado)
LEVY, D. Tuber and tuber quality of several potato cultivars as affected by seasonal high temperatures and by water deficit in a semiarid environment. Potato Research, v. 29, n. 1, p. 95-107, 1986.

LOPES, E.B. ; SILVA, F.C.P.; MOURA, F.T. Recomendações Técnicas para o cultivo da Batatinha (Solanum tuberosum L.) no Estado da Paraíba. João Pessoa: EMEPA - PB, 1996. 61 p. (EMEPA - PB. Circular técnica, 07).

MANRIQUE, L.A.; BARTHOLOMEW, D.P Growth and yield performance of potato grown at three elevations in Hawii. II. Dry matter production and efficiency of partitioning. Crop Science, v. 31, n. 2, p. 367-372, 1991.

MIDMORE, D.J.; ROCA, J. Influence of production and storage conditions on subsequent growth and tuber of potato (Solanum sp.) in the hot tropics. Journal Agricultural Science, v. 119, n. 1, p. 5-58, 1992.

PEREIRA, J.T.; SILVA, M.C.L.; FRANÇA, L.G.E.; WANDERLEY, L.J.G.; MELO, J.N.; SILVA, R.J.V. Avaliação de cultivares de batatinha (Solanum tuberosum L.) no Agreste de Pernambuco. Recife: IPA, 1993.7 p. (Comunicado técnico, 47).

SILVA, L.C. Comportamento de cultivares de batata no Estado da Paraíba. João Pessoa: EMEPA, 1987. 7 p. (EMEPA. Comunicado Técnico, 32).

SILVA, M.C.L.; PEREIRA, J.T.; MELO, J.N.; LIMA, L.E.; WANDERLEY, L.J.G.; CEZAR, F. O cultivo da batatinha (Solanum tuberosum L.) em condições de sequeiro no Agreste de Pernambuco. Recife: IPA, 1993. 9 p. (Comunicado técnico, 47).

WOLF, S.; MARANI, A.; RUDICH, J. Effect of temperature on carboydrate metabolism in potato plants. Journal of Experimental Botany, Oxford, v. 42, n. 238, p. 619-625, 1991. 